\title{
The impact of sustained immunization regimens on the antibody response to oligomannose glycans
}

Dung N. Nguyen, ${ }^{\text {a }}$ Richard L. Redman, ${ }^{\text {a }}$ Satoru Horiya, ${ }^{\mathrm{a}}$ Jennifer K. Bailey, ${ }^{\mathrm{a}}$ Bokai $\mathrm{Xu},{ }^{\mathrm{a}}$ Robyn L. Stanfield, ${ }^{\mathrm{b}} \mathrm{J}$. Sebastian Temme, ${ }^{\mathrm{a}}$ Celia C. LaBranche, ${ }^{\mathrm{c}}$ Shiyu

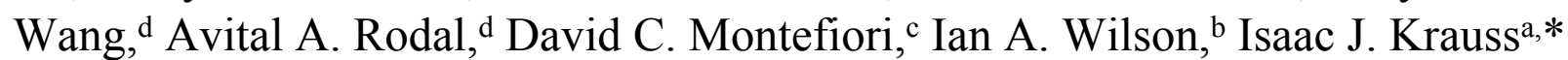
${ }^{a}$ Department of Chemistry, Brandeis University, Waltham, Massachusetts 02454-9110, USA;

${ }^{b}$ Department of Integrative Structural and Computational Biology and the Skaggs Institute for Chemical Biology, The Scripps Research Institute, La Jolla, California 92037, USA;

'Department of Surgery, Duke University Medical Center, Durham, North Carolina 27710, USA;

${ }^{d}$ Department of Biology, Brandeis University, Waltham, Massachusetts 02454-9110, USA

$\underline{\text { Table of contents }}$

Materials . $\mathrm{S3}$

Preparation of CRM-AcBr .53

Figure S1. MALDI-TOF MS of CRM-AcBr .... S4

Conjugation of glycopeptide g10F6 to CRM-AcBr .S4

Figure S2. MALDI-TOF MS of CRM-Ac-g10F6 . .55

Preparation of QS-21 liposome adjuvant .S6

Figure S3. TEM images of QS-21 liposome adjuvant . .57

Rabbit immunization regimen .57

Table S1. Exponential dose quantities .S8

ELISA protocol .S9

Figure S4. Instability of thiol maleimide linkage . S10

Figure S5. Rabbit serum response to BSA + Linker S11

Figure S6. MALDI-TOF mass spectra of BSA-Ac-glycopeptide conjugates for glycan microspecificity study 
Production of BG505 SOSIP Env for boosting

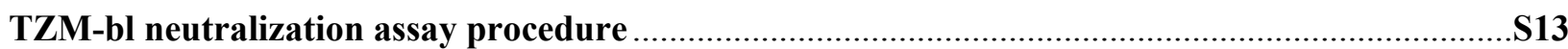

Table S2. TZM-bl neutralization assay of post-dose 3 sera ….................................................14

Table S3. TZM-bl neutralization assay of post-dose 6 sera …......................................................515

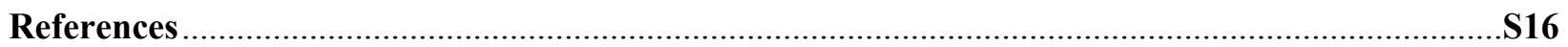




\section{Materials}

\begin{tabular}{ll}
\hline & Vendors/ Sources \\
\hline Cholesterol & MP Biomedicals \\
DOPC & Avanti Polar Lipids \\
$\mathrm{CRM}_{197}\left(\operatorname{ecoCRM}^{\mathrm{TM}}\right)$ & Fina Biosolutions LLC \\
QS-21 & Desert King
\end{tabular}

\section{Standard buffers for ELISA assay}

PBS

$137 \mathrm{mM} \mathrm{NaCl}, 2.7 \mathrm{mM} \mathrm{KCl}, 10 \mathrm{mM}$

$\mathrm{Na}_{2} \mathrm{HPO}_{4}, 1.8 \mathrm{mM} \mathrm{KH}{ }_{2} \mathrm{PO}_{4}$

Dulbecco's PBS

$137 \mathrm{mM} \mathrm{NaCl}, 2.7 \mathrm{mM} \mathrm{KCl}, 8.1 \mathrm{mM}$

$\mathrm{Na}_{2} \mathrm{HPO}_{4}, 1.5 \mathrm{mM} \mathrm{KH}_{2} \mathrm{PO}_{4}$

PBS-T

PBS, $0.05 \%$ Tween-20

PBS-T 5\% milk (blocking solution)

PBS-T, 5\% non-fat dried milk

PBS-T 1\% milk (dilution solution)

Prepared from dilution of PBS-T 5\% milk

Flat-bottomed ELISA plates (Nunc-Immuno)

Fisher Scientific

2G12 antibody

Polymun Scientific

Goat Anti-human antibody, Horseradish

Peroxidase (HRP) conjugate

3,3',5,5'-tetramethylbenzidine (TMB)

Invitrogen

$1 \mathrm{M}$ sulfuric acid

Abcam, Ab171522

Fisher Scientific

\section{Procedures}

Preparation of CRM-AcBr

$\mathrm{CRM}_{197}\left(\right.$ ecoCRM ${ }^{\mathrm{TM}}$, Fina Biosolutions LLC, $\left.1.0 \mathrm{mg}, 17 \mathrm{nmol}\right)$ was dissolved in $0.9 \mathrm{~mL}$ of PBS buffer ( $\mathrm{pH}$ 7.4). Bromoacetamido-PEG - -NHS ester (BroadPharm, BP-20569, $\left.\mathrm{BrCH}_{2}(\mathrm{CO}) \mathrm{NH}\left(\mathrm{CH}_{2} \mathrm{CH}_{2} \mathrm{O}\right)_{4}-\left(\mathrm{CH}_{2}\right)_{2}-\mathrm{CO}-\mathrm{NHS}\right)(1.2 \mathrm{mg}, 2.5 \mu \mathrm{mol}, 147$ equiv in $0.1 \mathrm{~mL}$ PBS buffer $\mathrm{pH}$ 7.4) was added for a final protein concentration of $1 \mathrm{mg} / \mathrm{mL}$. The reaction stood at room 
temperature for $1.5 \mathrm{~h}$. Excess bromoacetamido- $\mathrm{PEG}_{4}-\mathrm{NHS}$ ester was removed by buffer exchange through an Amicon centrifugal filter (30 kDa cutoff, Ultra-0.5, 4 rounds of dilution with PBS $\mathrm{pH}$ 8.5). The average molecular weight of the activated CRM-bromoacetamido (CRM-AcBr) was determined by MALDI-TOF analysis. A 6300-dalton average mass increase indicated an average of $\sim 17$ linkers per CRM molecule (Figure S1). BCA assay indicated recovery of $1.07 \mathrm{mg}$ of activated protein.

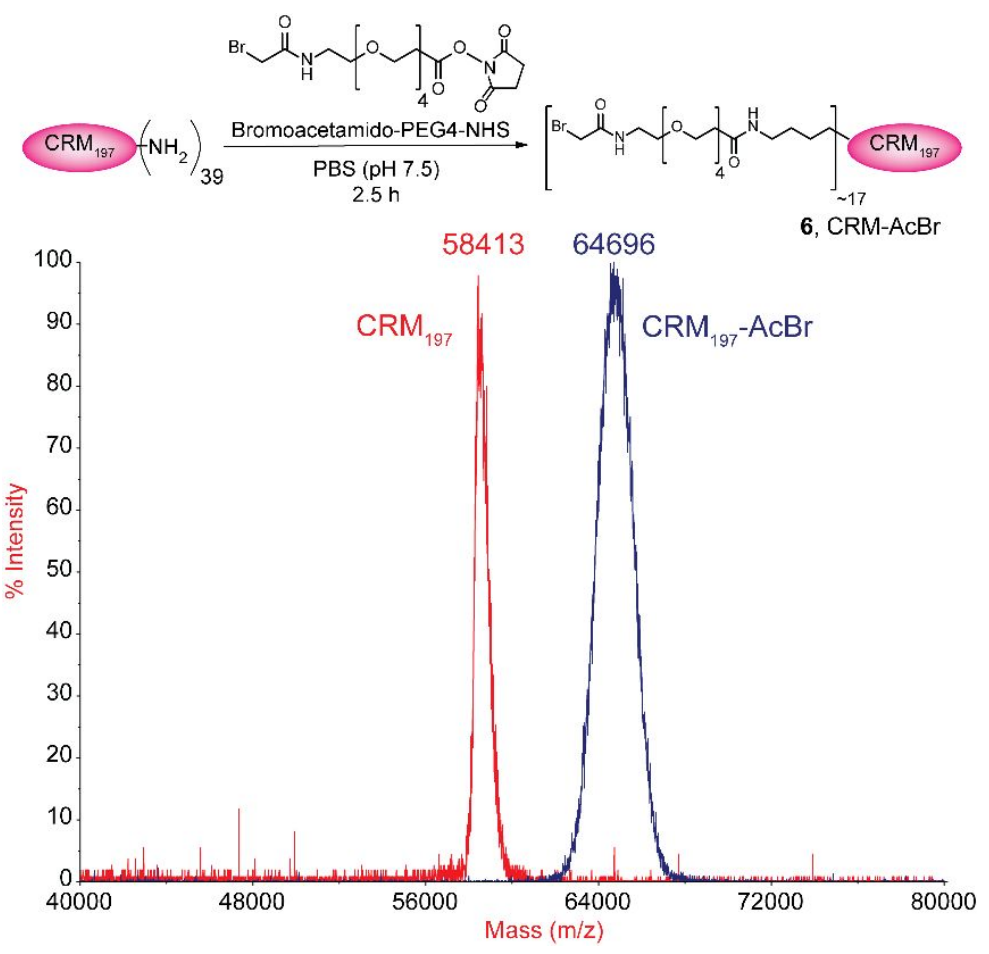

Figure S1. Synthesis of $\mathrm{CRM}_{197}$-bromoacetamido (CRM-AcBr) and MALDI-TOF-MS analysis of CRM$\mathrm{AcBr}$.

\section{Conjugation of glycopeptide g10F6 to CRM-AcBr}

Glycopeptide g10F6 ${ }^{1}(1.2 \mathrm{mg}, 95 \mathrm{nmol})$ in $285 \mu \mathrm{L}$ of water was treated with $1.9 \mu \mathrm{L}$ of $500 \mathrm{mM}$ TCEP·HCl/ 1M pH 7.8 Tris-HCl buffer ( $950 \mathrm{nmol}, 10$ equiv). Complete removal of the cysteine 
protecting group (-StBu disulfide) was confirmed by UPLC-ESI-MS after the reaction stood overnight at room temperature under $\mathrm{N}_{2}$. Excess TCEP was removed by buffer-exchange through an Amicon centrifugal filter (3-kDa cutoff, Ultra-0.5, $20 \mathrm{~min}$ in the first round of filtration, and 30 min for the second round) with PBS buffer ( $\mathrm{pH} 8.5)$. The deprotected glycopeptide was added to freshly-prepared $\mathrm{CRM}_{197}-\mathrm{AcBr}\left(0.7 \mathrm{mg}, 10.8 \mathrm{nmol}\right.$, average $\sim 17$ linkers $/ \mathrm{CRM}_{197}, 184 \mathrm{nmol}$ of bromoacetamide groups) in a total volume of $393 \mu \mathrm{L}$ PBS buffer (pH 8.5). The solution stood overnight under $\mathrm{N}_{2}$ at room temperature in the dark. The $\mathrm{CRM}_{197} \mathrm{~g} 10 \mathrm{~F} 6$ glycopeptide conjugate was purified by removing excess glycopeptide and salts through an Amicon centrifugal filter (30 $\mathrm{kDa}$ cutoff, Ultra-0.5, $5 \mathrm{~min}$ for at least 4 rounds of filtration, dilution with water). MALDI-TOF analysis indicated distribution of conjugates with median loading of $\sim 5.5$ glycopeptides per CRM molecule (median MW $\sim 132 \mathrm{KDa}$ ) (Figure S2). The unreacted bromoacetyl groups were then capped with $\beta$-mercaptoethanol (11.9 $\mu \mathrm{L}$ from $10 \mathrm{mM}$ stock, $119 \mathrm{nmol})$ in the dark for $1 \mathrm{~h}$ in 0.5 mL PBS ( $\mathrm{pH} 8.5)$ and the capped protein was then buffer-exchanged to water again by Amicon centrifugal filters ( $30 \mathrm{kDa}$ cutoff, Ultra-0.5, $5 \mathrm{~min}$ for at least 4 rounds of filtration). BCA quantification assay detected $1.25 \mathrm{mg}$ protein without the carbohydrate content, corresponding to 
$1.88 \mathrm{mg}(1.25 / 0.67)$ total mass of $\mathrm{CRM}_{197}$-Ac-g10F6 glycopeptide conjugate.

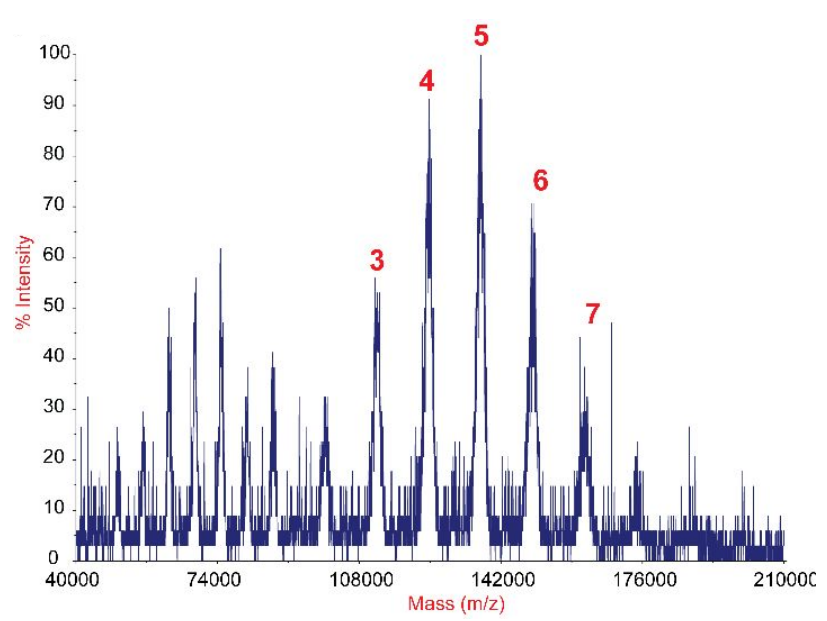

Figure S2. MALDI-TOF MS analysis of CRM-Ac-g10F6 glycopeptide conjugate. Smaller peaks to the left are doubly charged ions.

\section{Preparation of QS-21 liposome adjuvant}

A liposome formulation of QS-21 saponin adjuvant was formulated with cholesterol and 1,2dioleoyl-sn-glycero-3-phosphocholine (DOPC) as described by Collin and coworkers. ${ }^{2}$ Briefly, DOPC (50 mg, $1.2 \mathrm{~mL}$ from 40mg/mL of DOPC stock solution) and cholesterol (12.5 mg, $1.2 \mathrm{~mL}$ from $10 \mathrm{mg} / \mathrm{mL}$ cholesterol stock solution) were dissolved in $2.3 \mathrm{~mL}$ chloroform in a $25 \mathrm{~mL}$ round bottom flask. The solvent was carefully evaporated in vacuo to yield a transparent lipid film, which was then left under vacuum for $1 \mathrm{~h}$. The film was then hydrated in Dulbecco's PBS buffer ( $5 \mathrm{~mL})$ at $37{ }^{\circ} \mathrm{C}$ for at least $1 \mathrm{~h}$. The hydrated liposomes were extruded for 10 cycles through $0.4 \mu \mathrm{m}$ polycarbonate membrane filters, then 10 cycles through $0.2 \mu \mathrm{m}$ filters, and finally 15 cycles through $0.1 \mu \mathrm{m}$ filters into $12 \mathrm{~mL}$ polypropylene tubes. Commercially available lyophilized QS$21(3 \mathrm{mg})$ was added to $6 \mathrm{~mL}$ of DPBS -/- and allowed to sit for 1 hour at room temperature for complete dissolution of QS-21. The QS-21 solution (2 mg, $4 \mathrm{~mL})$ was added to the $12 \mathrm{~mL}$ polypropylene tube containing the liposome suspension $(4 \mathrm{~mL})$. The tube was gently inverted five 
times and stored at $4{ }^{\circ} \mathrm{C}$. For transmission electron microscopy (TEM), samples were applied to copper grids coated with continuous carbon, negatively stained with $2 \%$ uranyl acetate (JT Baker Chemical Co., Phillipsburg, NJ), and imaged using an FEI Morgagni transmission electron microscope (FEI, Hillsboro, OR) operating at $80 \mathrm{kV}$ and equipped with a $1 \mathrm{k} \times 1 \mathrm{k}$ charge coupled device (CCD) camera (Gatan, Pleasanton, CA). TEM (Figure S3) showed the liposomes to be primarily 100-250 nm in size, with no substantial change observed after two weeks storage at 37 ${ }^{\circ} \mathrm{C}$.
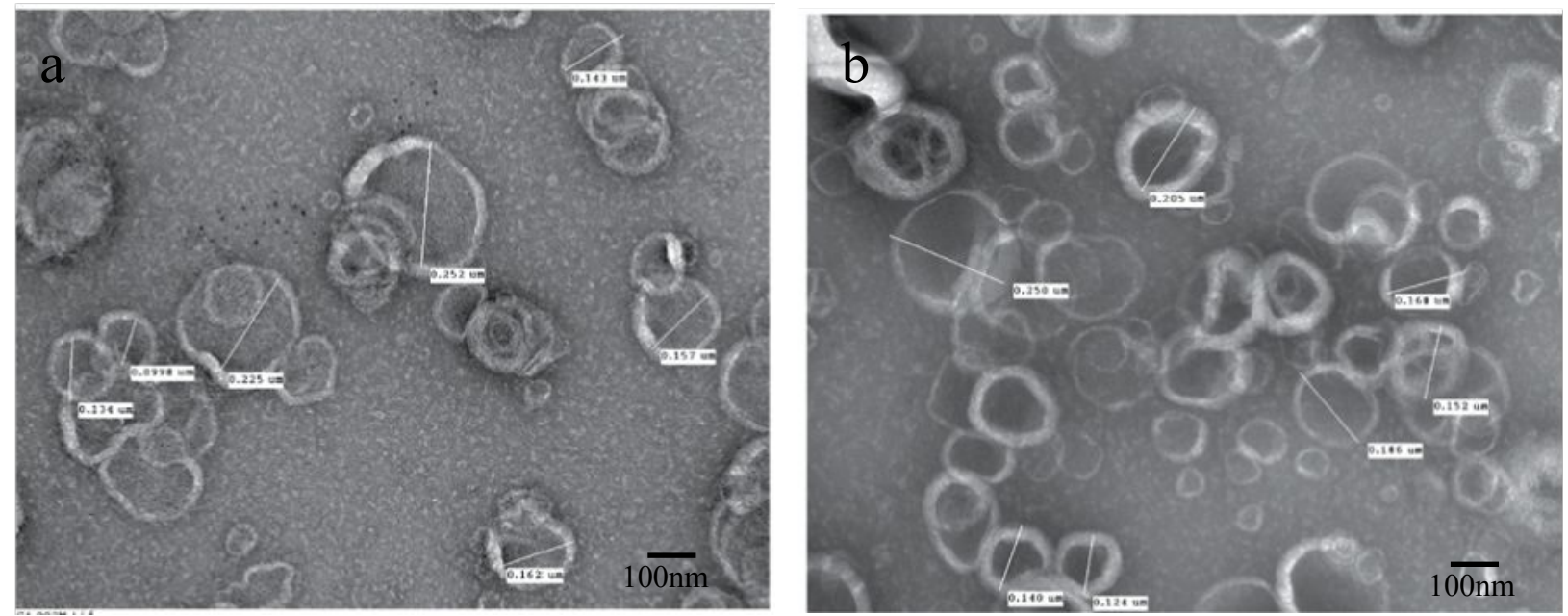

Figure S3. Negative stain Transmission Electron Microscopy (TEM) images of liposome/QS-21 adjuvant combined with g10F6-CRM immunogen. a) Day 0. b) After incubation at $37^{\circ} \mathrm{C}$ for 14 days. Liposomes were stained with $2 \%$ uranyl acetate.

\section{Rabbit immunization regimen}

Three groups of six female New Zealand White rabbits were housed at Toxikon Inc. Animals were immunized as described below with $\mathrm{CRM}_{197}$-Ac-g10F6 glycopeptide conjugate (prepared as described above) and QS-21 liposomes (formulated as described above). 
Bolus group: Animals received bilateral subcutaneous bolus injections $(200 \mu \mathrm{L}$ split between two sites) comprising conjugate containing total $50 \mu \mathrm{g}$ of glycopeptide and liposomes containing total $50 \mu \mathrm{g}$ of QS-21 adjuvant per animal. Diluent was sterile phosphate-buffered saline (Dulbecco's PBS). This immunization was repeated at 4 weeks and 8 weeks. BG505T332N SOSIP boost injections were performed at weeks 16, 20 and 24 with $50 \mu \mathrm{g}$ SOSIP protein and liposome containing $50 \mu \mathrm{g}$ QS-21, in $400 \mu \mathrm{L}$ distributed between two sites.

Exponential group: Animals received bilateral subcutaneous, exponentially increasing doses of conjugate + QS-21 liposomes on days 0,2, 4, 6, 8, 10 and 12. Regardless of dose, the injection volume was diluted to $200 \mu \mathrm{L}$ total for two sites; the exponentially increasing amounts of conjugate and QS-21 liposomes in these injections contained the quantities of glycopeptide and QS-21 indicated below (Table S1). Diluent was sterile phosphate-buffered saline (Dulbecco's PBS). This immunization cycle was repeated at 4 weeks and 8 weeks. BG505T332N SOSIP boost injections were performed as bolus injections at weeks 16, 20 and 24 with $50 \mu \mathrm{g}$ SOSIP protein and liposome containing $50 \mu \mathrm{g}$ QS-21, in $400 \mu \mathrm{L}$ distributed between two sites.

\begin{tabular}{|l|l|l|}
\hline Day & QS-21 & g10F6 \\
\hline 0 & $0.1 \mu \mathrm{g}$ & $0.1 \mu \mathrm{g}$ \\
\hline 2 & $0.26 \mu \mathrm{g}$ & $0.26 \mu \mathrm{g}$ \\
\hline 4 & $0.68 \mu \mathrm{g}$ & $0.68 \mu \mathrm{g}$ \\
\hline 6 & $1.8 \mu \mathrm{g}$ & $1.8 \mu \mathrm{g}$ \\
\hline 8 & $4.6 \mu \mathrm{g}$ & $4.6 \mu \mathrm{g}$ \\
\hline 10 & $12 \mu \mathrm{g}$ & $12 \mu \mathrm{g}$ \\
\hline 12 & $31 \mu \mathrm{g}$ & $31 \mu \mathrm{g}$ \\
\hline cumulative & $50 \mu \mathrm{g}$ & $50 \mu \mathrm{g}$ \\
\hline
\end{tabular}

Table S1. Exponential dose quantities used in rabbit immunization

Osmotic pump group: Animals received bilateral continuous infusions of glycopeptide conjugate via subcutaneously implanted Alzet ${ }^{\circledR}$ mini-pumps. Each 2-week $100 \mu \mathrm{L}$ pump was loaded with 
conjugate containing $12.5 \mu \mathrm{g}$ glycopeptide and 12.5 $\mu \mathrm{g}$ of QS-21 (in liposome formulation); pumps were implanted bilaterally into subcutaneous pockets created in the dorsum of each animal on weeks 0,4 , and 8 . At the end of each two-week pump infusion, each rabbit received bilateral subcutaneous bolus injections of conjugate containing $12.5 \mu \mathrm{g}$ of glycopeptide and $12.5 \mu \mathrm{g}$ of QS21, so that each immunization cycle totaled $50 \mu \mathrm{g}$ of immunogen and $50 \mu \mathrm{g}$ of QS-21. Serum samples were collected one week after the completion each 2-week infusion. BG505T332N SOSIP boost injections were performed as bolus injections at weeks 16, 20 and 24 with $50 \mu \mathrm{g}$ SOSIP protein and liposome containing $50 \mu \mathrm{g}$ QS-21, in $400 \mu \mathrm{L}$ distributed between two sites.

\section{ELISA protocol}

All steps were performed as follows unless stated otherwise. High-protein-binding flat-bottomed Maxisorp ELISA plates were coated with 120-2000 ng/mL antigen in coating buffer (100 $\mu \mathrm{L} /$ well) and incubated at $4{ }^{\circ} \mathrm{C}$ overnight. Glycopeptide conjugates and carrier proteins were coated at 200 $\mathrm{ng} / \mathrm{mL}$ concentration, and SOSIP trimer was coated at $120 \mathrm{ng} / \mathrm{mL}$ (for sera post-SOSIP boost) or $2 \mu \mathrm{g} / \mathrm{mL}$ (for sera prior to SOSIP boost). The wells were washed twice with PBS-T (200 $\mu \mathrm{L})$ and then blocked for $1 \mathrm{~h}$ at room temperature with 5\% fat-free milk PBS-T (200 $\mu \mathrm{L} /$ well). After washing again twice with PBS-T, the wells were then incubated with either 3-fold, 4-fold or 5-fold serial dilutions of rabbit serum (starting at different concentrations: either 1:10 or 1:100) in 1\% fat-free milk in PBS-T for $2 \mathrm{~h}$ at room temperature. The wells were washed 3 times before incubating with $100 \mu \mathrm{L}$ of an HRP-conjugated sheep anti-rabbit antibody at 1: 10,000 dilution for $1 \mathrm{~h}$ at room temperature. After 3 washes, the wells were developed by adding $100 \mu \mathrm{L}$ of TMB solution for 3-35 min. The reaction was stopped by adding $100 \mu \mathrm{L}$ of $1 \mathrm{M}$ sulfuric acid and absorbance was measured at $450 \mathrm{~nm}$ wavelength. All measurements were performed in triplicate, except that the prebleed sera were tested in duplicate. 

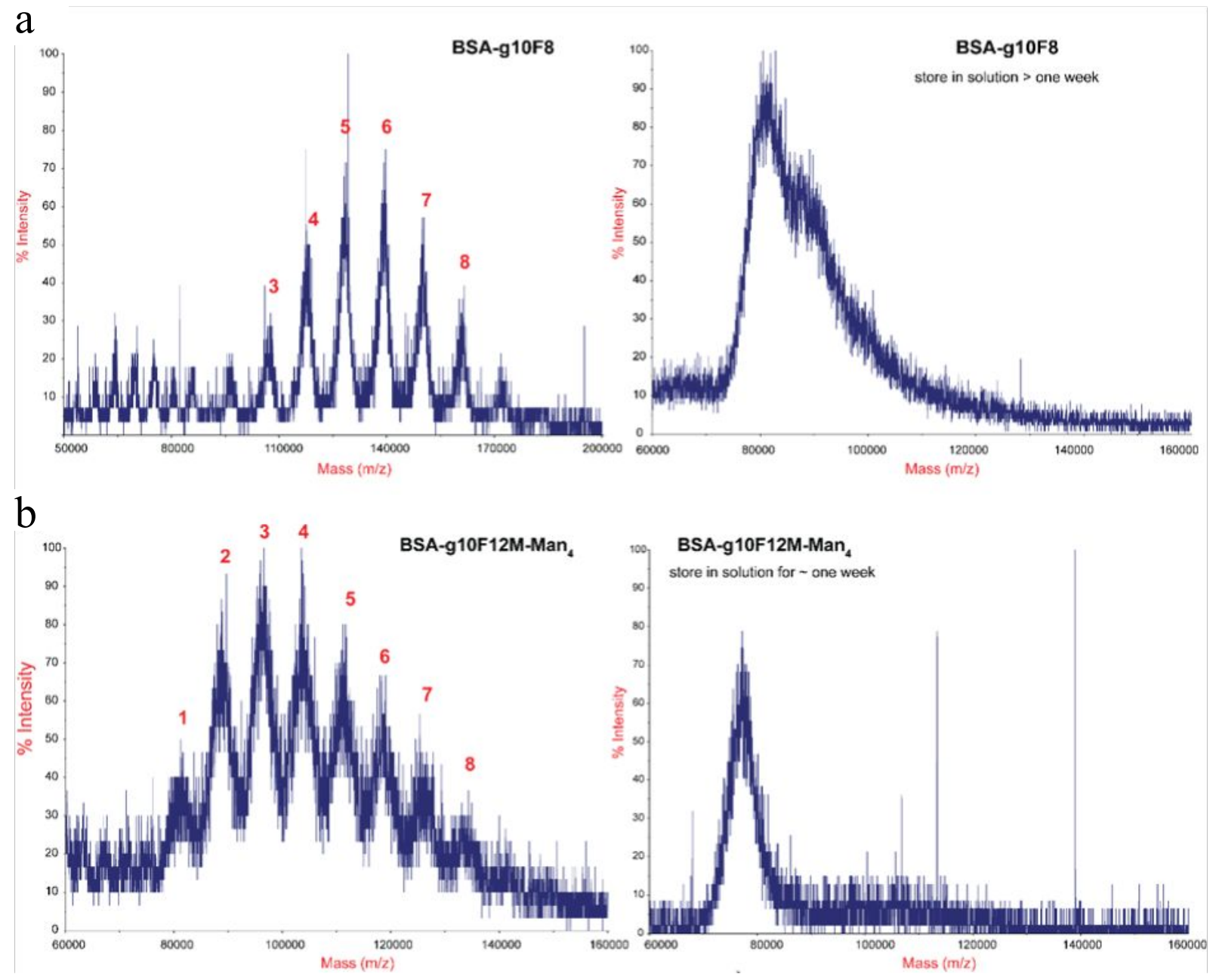

Figure S4. Instability of the thiol-maleimide linkage. a) MALDI-TOF mass spectra of maleimide-linked g10F8-BSA conjugate ${ }^{1}$ before and after one week of storage in water at $4{ }^{\circ} \mathrm{C}$. b) MALDI-TOF mass spectra of maleimide-linked Man $_{4}-\mathrm{g} 10 \mathrm{~F} 12 \mathrm{M}-\mathrm{BSA}$ conjugate ${ }^{1}$ before and after one week of storage in water at $4{ }^{\circ} \mathrm{C}$. 


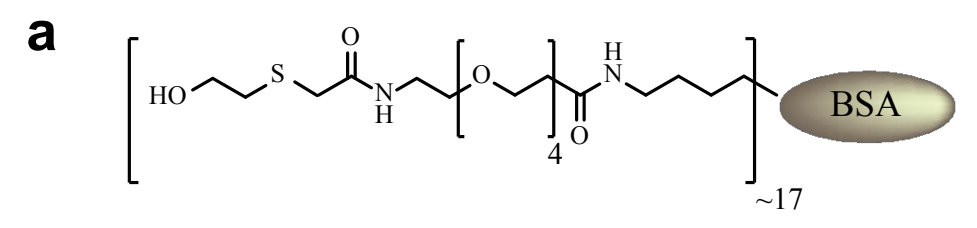

\begin{tabular}{|c|c|c|}
\hline Bolus & Exponential & Pump \\
\hline$--*$ & $--*$ & $--^{*}$ \\
\hline $1: 256$ & -.* & -.* \\
\hline$--^{*}$ & -.* & $1: 85$ \\
\hline$--^{*}$ & $--^{*}$ & $--^{*}$ \\
\hline -.* & --* & -.* \\
\hline -.* & --* & $--^{*}$ \\
\hline
\end{tabular}

Figure S5. Rabbit serum response to linker used in the $\mathrm{CRM}_{197} \mathrm{~g} 10 \mathrm{~F} 6$ glycopeptide conjugates. a) capped BSA+linker used in ELISA to detect anti-linker response. b) Post-dose 2 serum ELISA $\mathrm{EC}_{50}$ values (serum dilutions). ${ }^{*}\left(\mathrm{OD}_{50}\right.$ below 0.1 at minimum serum dilution of 1:50). 

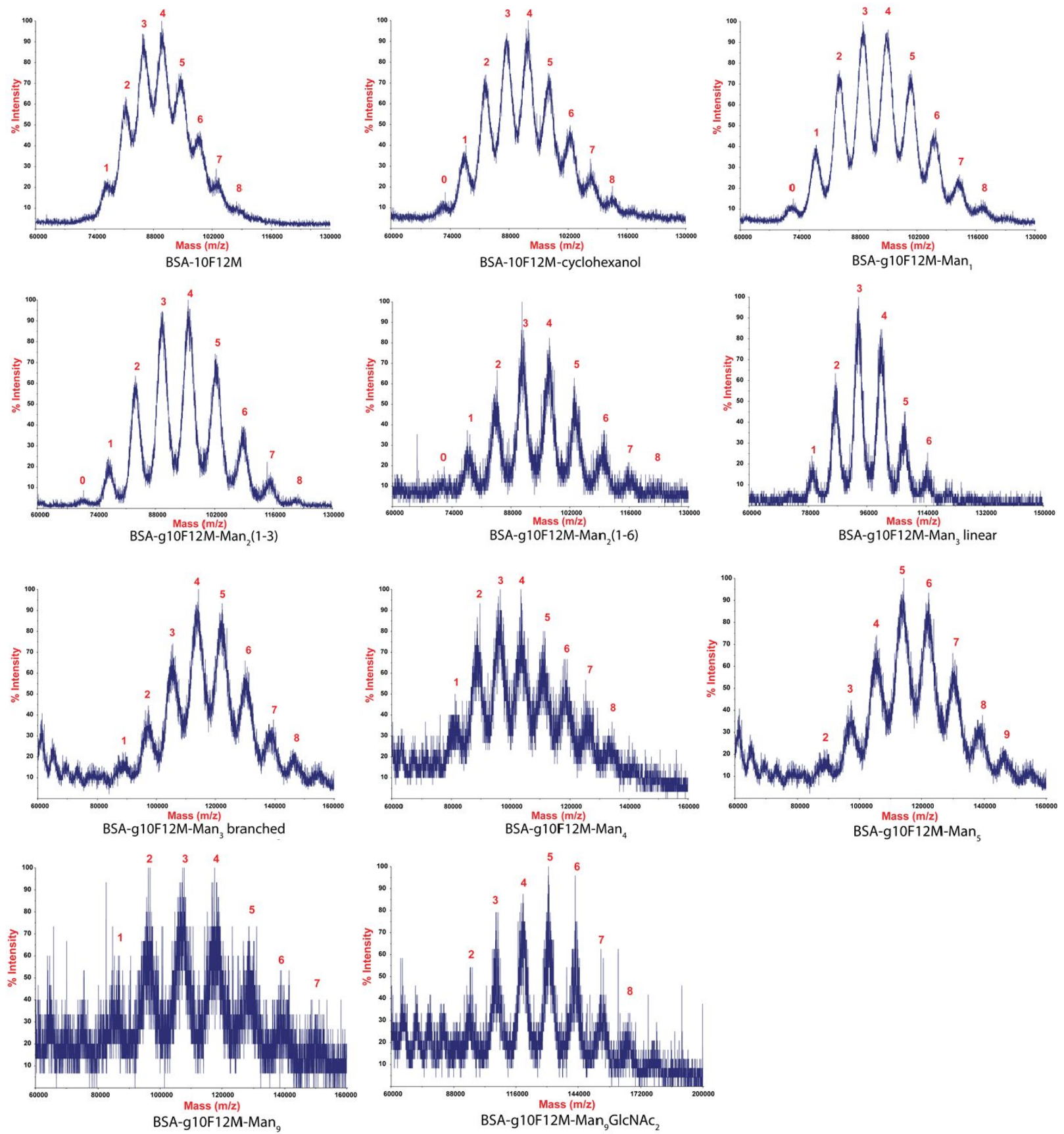

Figure S6. MALDI-TOF MS of BSA-Ac-glycopeptide conjugates used in microspecificity study. The red numbers indicate the number of glycopeptides per BSA protein molecule. More closely clustered peaks at lower $\mathrm{m} / \mathrm{z}$ are doubly charged ions. Conjugates were prepared analogously to CRM197-Ac-g10F6 using glycopeptides that were reported previously. ${ }^{1}$ 


\section{Production of BG505 SOSIP Env for boosting}

BG505 SOSIP.664 (T332N) used for boosting was co-expressed with furin in 293 Freestyle cells (ThermoFisher) following standard protocols. ${ }^{3}$ SOSIP was purified from the media by Galanthus Nivalis Lectin affinity chromatography (Vector Labs) followed by size exclusion chromatography (Superdex 200, 16/60, GE).

\section{TZM-bl neutralization assay procedure}

Neutralizing antibody activity in serum samples was measured in duplicate in 96-well culture plates by using Tat-regulated luciferase (Luc) reporter gene expression to quantify reductions in virus infection in TZM-bl cells. TZM-bl cells were obtained from the NIH AIDS Research and

Reference Reagent Program, as contributed by John Kappes and Xiaoyun Wu. Assays were performed with HIV-1 Env-pseudotyped viruses essentially as previously described. ${ }^{4}$ Serum samples were heat-inactivated at $56^{\circ} \mathrm{C}$ for $1 \mathrm{hr}$, then diluted over a range of 1:20 to 1:43740 in cell culture medium and pre-incubated with virus $(\sim 150,000$ relative light unit equivalents) for $1 \mathrm{hr}$ at $37^{\circ} \mathrm{C}$ before addition of cells. Following a $48 \mathrm{hr}$ incubation, cells were lysed and Luc activity determined using a microtiter plate luminometer and BriteLite Plus Reagent (Perkin Elmer). Neutralization titers are the sample dilution at which relative luminescence units (RLU) were reduced by $50 \%$ compared to RLU in virus control wells after subtraction of background RLU in cell control wells. 


\begin{tabular}{|c|c|c|c|c|c|c|c|}
\hline & & \multicolumn{6}{|c|}{ ID $_{50}$ in TZM-bl Cells ${ }^{1}$} \\
\hline & & $\begin{array}{l}\text { SVA- } \\
\text { MLV }\end{array}$ & MW965.26 & BG505/T332N & JR-FL & $\begin{array}{c}\text { JR- } \\
\text { FL.V1 3Q } \\
\end{array}$ & CH0848.3.d949.10.17.N133D.N138T \\
\hline & & $\begin{array}{l}\text { Neg } \\
\text { Ctrl } \\
\end{array}$ & Clade C & Clade A & $\begin{array}{c}\text { Clade } \\
\text { B } \\
\end{array}$ & Clade B & Clade C \\
\hline & & & Tier 1A & Tier 2 & Tier 2 & Tier 1A & Tier 2 \\
\hline Study ID & $\begin{array}{c}\text { Anima } \\
\text { I ID }\end{array}$ & ID\#8075 & ID\#7847 & ID\#9212 & ID\#730 & ID\#9113 & ID\#9210 \\
\hline Bolus & 1101 & $<20$ & $<20$ & $<20$ & $<20$ & $<20$ & $<20$ \\
\hline Bolus & 1102 & $<20$ & $<20$ & $<20$ & $<20$ & $<20$ & $<20$ \\
\hline Bolus & 1103 & $<20$ & $<20$ & $<20$ & $<20$ & $<20$ & $<20$ \\
\hline Bolus & 1104 & $<20$ & $<20$ & $<20$ & $<20$ & $<20$ & $<20$ \\
\hline Bolus & 1105 & $<20$ & $<20$ & $<20$ & $<20$ & $<20$ & $29^{*}$ \\
\hline Bolus & 1106 & $<20$ & $<20$ & $<20$ & $<20$ & $<20$ & $<20$ \\
\hline Exponential & 2101 & $<20$ & $<20$ & $<20$ & $<20$ & $<20$ & $<20$ \\
\hline Exponential & 2102 & $<20$ & $<20$ & $<<20$ & $<20$ & $<20$ & $<20$ \\
\hline Exponential & 2103 & $<20$ & $<20$ & $<20$ & $<20$ & $<20$ & $<20$ \\
\hline Exponential & 2104 & $<20$ & $<20$ & $<20$ & $<20$ & $<20$ & $<20$ \\
\hline Exponential & 2105 & $<20$ & $<20$ & $<20$ & $<20$ & $<20$ & $<20$ \\
\hline Exponential & 2106 & $<20$ & $<20$ & $<20$ & $<20$ & $<20$ & $<<20$ \\
\hline Pump & 3101 & $<20$ & $<20$ & $<20$ & $<20$ & $<20$ & $<20$ \\
\hline Pump & 3102 & $<20$ & $<20$ & $<20$ & $<20$ & $<20$ & $<20$ \\
\hline Pump & 3103 & $<20$ & $<20$ & $<20$ & $<20$ & $<20$ & $<20$ \\
\hline Pump & 3104 & $<20$ & $<20$ & $<20$ & $<20$ & $<20$ & $<20$ \\
\hline Pump & 3105 & $<20$ & $<20$ & $<20$ & $<20$ & $<20$ & $<20$ \\
\hline Pump & 3106 & $<20$ & $<20$ & $<20$ & $<20$ & $<20$ & $<20$ \\
\hline $\begin{array}{r}\mathrm{CH} 01-31 \\
\text { contr } \\
\end{array}$ & itive & $>25$ & 1.63 & 0.02 & 0.02 & $<0.01$ & 0.43 \\
\hline
\end{tabular}

${ }^{I}$ Values are the serum dilution at which relative luminescence units (RLUs) were reduced $50 \%$ compared to virus control wells (no test sample).

*Both replicates exhibited concentration-dependent signal with RLU decreasing at higher serum concentrations.

Table S2. TZM-bl Neutralization assay results of post-dose 3 sera (after three immunizations with CRM-Ac-g10F6 glycopeptide conjugate, prior to SOSIP boost). 


\begin{tabular}{|c|c|c|c|c|}
\hline & & \multicolumn{3}{|c|}{ ID $_{50}$ in TZM-bl Cells ${ }^{1}$} \\
\hline & & \multirow{2}{*}{$\begin{array}{l}\text { SVA-MLV } \\
\text { Neg Ctrl }\end{array}$} & CH0848.3.d949.10.17.N133D.N138T & BG505/T332N \\
\hline & & & Clade C & Clade A \\
\hline & & & Tier 2 & Tier 2 \\
\hline Group & Animal ID & ID\#8075 & ID\#9479 & ID\#9212 \\
\hline Bolus & 1101 & $<20$ & & $<20$ \\
\hline Bolus & 1102 & $<20$ & & 89 \\
\hline Bolus & 1103 & $<20$ & & $<20$ \\
\hline Bolus & 1104 & $<20$ & & 218 \\
\hline Bolus & 1105 & $<20$ & & 259 \\
\hline Bolus & 1106 & $<20$ & & 241 \\
\hline Exponential & 2101 & $<20$ & & $<20$ \\
\hline Exponential & 2102 & $<20$ & & 87 \\
\hline Exponential & 2103 & $<20$ & & 42 \\
\hline Exponential & 2104 & $<20$ & & 179 \\
\hline Exponential & 2105 & $<20$ & & 413 \\
\hline Exponential & 2106 & $<20$ & & 40 \\
\hline Pump & 3101 & $<20$ & & 371 \\
\hline Pump & 3102 & $<20$ & & 104 \\
\hline Pump & 3103 & $<20$ & & 820 \\
\hline Pump & 3104 & $<20$ & & 128 \\
\hline Pump & 3105 & $<20$ & & 36 \\
\hline Pump & 3106 & $<20$ & & 270 \\
\hline $\mathrm{CH} 01-31(\mathrm{p}$ & control) & $>25$ & 0.3 & 0.049 \\
\hline
\end{tabular}

${ }^{1}$ Values are the serum dilution or antibody concentration (in $\mathrm{ug} / \mathrm{ml}$ ) at which relative luminescence units (RLUs) were reduced $50 \%$ compared to virus control wells (no test sample).

Table S3. TZM-bl Neutralization assay results of post-dose 6 sera (after three SOSIP boost immunizations). 


\section{References}

1. $\quad$ Nguyen, D. N.; Xu, B.; Stanfield, R. L.; Bailey, J. K.; Horiya, S.; Temme, J. S.; Leon, D. R.; LaBranche, C. C.; Montefiori, D. C.; Costello, C. E.; Wilson, I. A.; Krauss, I. J., Oligomannose Glycopeptide Conjugates Elicit Antibodies Targeting the Glycan Core Rather than Its Extremities. ACS Cent. Sci. 2019, 5 (2), 237-249.

2. $\quad$ Brunner, L.; Barnier-Quer, C.; Collin, N., QS-21 Adjuvant: Laboratory-Scale Purification Method and Formulation Into Liposomes. In Vaccine Adjuvants: Methods and Protocols, Fox, C. B., Ed. Springer New York: New York, NY, 2017; pp 73-86.

3. $\quad$ Sanders, R. W.; Derking, R.; Cupo, A.; Julien, J. P.; Yasmeen, A.; de Val, N.; Kim, H. J.; Blattner, C.; de la Pena, A. T.; Korzun, J.; Golabek, M.; de los Reyes, K.; Ketas, T. J.; van Gils, M. J.; King, C. R.; Wilson, I. A.; Ward, A. B.; Klasse, P. J.; Moore, J. P., A Next-Generation Cleaved, Soluble HIV-1 Env Trimer, BG505 SOSIP.664 gp140, Expresses Multiple Epitopes for Broadly Neutralizing but Not Non-Neutralizing Antibodies. PLoS Pathog 2013, 9 (9), e1003618.

4. Montefiori, D. C., Measuring HIV neutralization in a luciferase reporter gene assay. Meth. Molec. Biol. 2009, 485, 395-405. 